\title{
GAMIFICAÇÃO: A CRIATIVIDADE COMO ELEMENTO DE ENGAJAMENTO NO PROCESSO AVALIATIVO
}

\section{GAMIFICATION: CREATIVITY AS AN ENGAGING FACTOR IN THE EVALUATION PROCESS}

\author{
Paulo Roberto Martins Coelho ${ }^{1}$, Esp. \\ Mario Meireles Teixeira ${ }^{2}$, Dr. \\ Rosane de Fatima Antunes Obregon ${ }^{3}$, Dra. \\ Ana Lucia Alexandre de Oliveira Zandomeneghi ${ }^{4}$, Dra. \\ (1) Universidade Federal do Maranhão \\ e-mail:prmcoelho@gmail.com \\ (2) Universidade Federal do Maranhão \\ e-mail:mario@deinf.ufma.br \\ (3) Universidade Federal do Maranhão \\ e-mail: antunesobregon@gmail.com \\ (4) Universidade Federal do Maranhão \\ e-mail: anazandomeneghi@hotmail.com
}

Processo criativo, educação, Multi User Dungeon

O presente artigo tem por objetivo posicionar o processo criativo e gamificação no contexto educacional, discutindo até que ponto esses elementos promovem um verdadeiro engajamento dos estudantes e como a prática do design influencia na percepção social e cultural desses elementos. Apresenta também um roteiro e aplicação de técnica Multi-User Dungeon para auxiliar o processo de gamificação na educação, de modo a gerar discussões críticas mais aprofundadas sobre mecânicas de jogos e dinâmicas de jogos.

\section{Creative process, education, Multi User Dungeon}

This article aims to position creative process and gamification in the educational context, discussing to what extent these elements promote a real engagement of students and how the practice of design influences on social and cultural perception of these elements. It also presents a roadmap and use of Multi-User Dungeon technique to assist the gamification process in education, in order to generate more in-depth critical discussion of game mechanics and game dynamics.

\section{Introdução}

Apesar de documentado desde 2008, o termo "gamificação" ainda carece de conceitos acadêmicos aprofundados [DETERDING et al., 2011]. Podemos entender por gamificação o uso de elementos de jogos em um contexto de não-jogo
Realização:

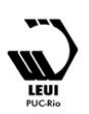




\section{$16^{\circ}$ \\ ERGODESIGN USIHC CINAHPA}

que motiva determinada ação [BODNAR et al., 2016; DE-MARCOS; GARCIA-LOPEZ; GARCIA-CABOT, 2016; DETERDING et al., 2011; WERBACH; HUNTER, 2012].

Jogos são geralmente concebidos dentro de uma estrutura que permite que jogadores joguem quantas vezes forem necessárias ou desejadas, reiniciando o progresso ou continuando de onde parou. Isso torna os erros mais toleráveis e, por consequência, no processo de gamificação, torna o usuário mais propenso a experimentar sem medo as atividades propostas [HANUS; FOX, 2015].

Tornar os estudantes motivados a participarem das aulas e interagirem com os processos de ensino é uma figura central do processo educacional. Aplicar a mecânica dos jogos à atividades de aprendizado deve, então, aumentar sua motivação para aprender [HANUS; FOX, 2015].

Nessa linha, a pesquisa tem por objetivo analisar as possibilidades da gamificação no processo avaliativo de uma disciplina de curso de graduação e o potencial de gerar maior engajamento dos alunos com s conteúdos pretendidos. Para o estudo de caso será analisada a disciplina Semiótica, do curso de Design da Universidade CEUMA.

\section{Criatividade}

Guilford [1977] afirma que a criatividade é essencialmente um apanhado de habilidades singulares. Ainda separa o termo em criatividade artística e científica, afirmando que a primeira é dependente de "conteúdo figurativo, simbólico ou semântico" [GUILFORD, 1977 p. 13].

Para Freitas-Magalhães [2003], enquanto estabelecimento cultural, a criatividade está intimamente ligada a relações interpessoais, ora tida como construto, ora tida como fruto do meio e do seu criador.

Sendo a criatividade um processo de relação intercultural [FREITAS-MAGALHÃES, 2003], podemos trazer à tona os questionamentos de Morais [2011, p. 10]: O que requer criatividade? Segundo a autora, ser criativo é ser possuído por $16^{\circ}$ Ergodesign - Congresso Internacional de Ergonomia e Usabilidade de Interfaces Humano Tecnológica: Produto, Informações Ambientes Construídos e Transporte

$16^{\circ}$ USIHC - Congresso Internacional de Ergonomia e Usabilidade de Interfaces Humano Computador

CINAHPA | 2017 - Congresso Internacional de Ambientes Hipermídia para Aprendizagem.

um sentimento exacerbado de motivação, para que não apenas se reproduzam conceitos, mas de fato se crie algo. Frequentemente vista como associações de informações [DINEEN, 2006; MEDNICK, 1962], Morais [2011] ainda afirma que não há associações sem a posse da informação, culminando no conhecimento não limitado ao que se domina, mas ao conhecimento multidisciplinar, sendo a criatividade uma atribuição:

Criatividade é então esta co-incidência, esta coexistência necessária de factores que implicam, na sua maioria, a relação do indivíduo com o meio e que podem ser (talvez com as excepções das aptidões e do olhar de outro) mutáveis nesse indivíduo. [MORAIS, 2011, p. 12]

Dada a relação entre conhecimento e cultura, há que se entender $o$ aspecto social da criatividade. Miranda et al [2015] afirma que a criatividade desempenha papel importante no desenvolvimento de organizações e que pessoas dotadas de capacidade criativa podem despontar como diferenciais dentro dessas organizações. Assim, necessitando de ambiente social para a prática do processo criativo, fica evidente que, em ambientes propícios à socialização, as possibilidades de desenvolvimento de processos criativos tornam-se muito maiores.

\section{Gamificação e jogos na educação}

Jogos são obras narrativas, mobilizando "não apenas as capacidades relacionadas ao prazer do jogo pelo jogo, mas sim ao prazer de descobrir e conhecer novos mundos, adentrando mundos possíveis." [MUNGIOLI, 2014]. Como resultado das experiências narrativas, temos uma experiência cognitiva, gerador de emoções e personalidades quando do seu envolvimento em histórias construídas de maneira organizada e estruturada [BUSARELLO et al, 2014].

$\mathrm{O}$ aspecto interativo dos jogos permitem que o jogador viva determinada história, controlando o desenrolar de sua própria história de acordo com a narrativa proposta.

Infelizmente, apenas um pequeno número de jogos educacionais tornou-se populares, como a série
Realização:
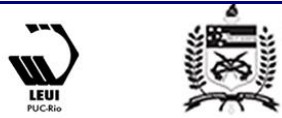


\section{$16^{\circ}$ \\ ERGODESIGN USIHC CINAHPA}

"Carmen Sandiego" [ALESSI; R.TROLLIP, 2001] em que, através de dicas, jogadores precisavam seguir pistas baseadas em informações sócioeconômicas dos países. Assim, para que jogos sejam considerados educacionais não basta apenas adicionar conteúdo educacional a eles [HAWORTH; SEDIG, 2011].

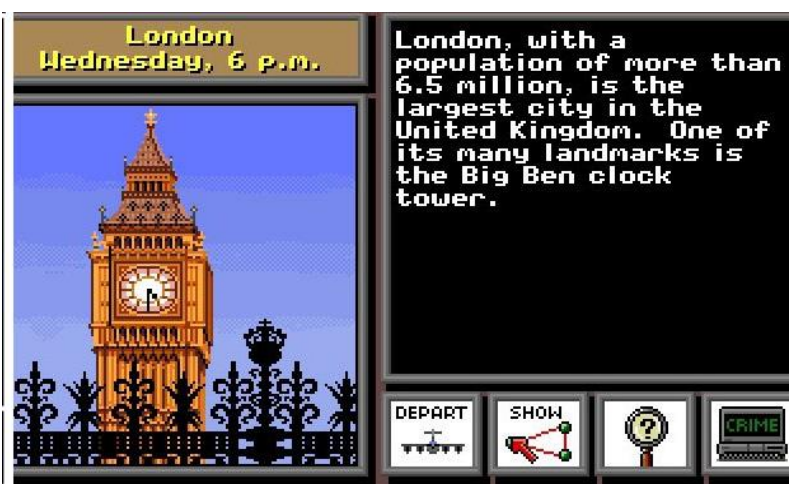

Figura 1: Tela do jogo Where in the World is Carmen Sandiego?

De-Marcos et al. [2016] afirma que o potencial dos jogos enquanto ferramentas educacionais tem se expandido à medida que se expande $\mathrm{o}$ interesse $\mathrm{e}$ as expectativas de um mundo gamificado, despertando a atenção de educadores e instituições interessadas no engajamento e experiências de aprendizado que os jogos propõem. Por um lado, jogos educativos treinam jogadores utilizando mecânicas e objetivos dos jogos sérios. De outro, a gamificação motivando jogadores em contextos diversos.

Outro ponto que podemos considerar é o alcance que redes sociais conseguem no cotidiano, compartilhando e colaborando, interagindo e oferecendo muitas possibilidades de personalização de conteúdo. Segundo De-Marcos et al. [2016, p. 100], a gamificação social:

Visa unir gamificação e redes sociais para combinar as duas abordagens para criar experiências de usuário focadas no aspecto social e envolventes. De uma perspectiva educacional, pode mobilizar os aspectos motivacionais da gamificação para estimular a participação e engajamento com o conteúdo de aprendizado e outros participantes. Redes sociais facilitam a comunicação, explicitam laços sociais e pontuam $16^{\circ}$ Ergodesign - Congresso Internacional de Ergonomia e Usabilidade de Interfaces Humano Tecnológica: Produto, Informações Ambientes Construídos e Transporte

$16^{\circ}$ USIHC - Congresso Internacional de Ergonomia e Usabilidade de Interfaces Humano Computador

CINAHPA | 2017 - Congresso Internacional de Ambientes Hipermídia para Aprendizagem. conteúdos relevantes para os participantes. [DEMARCOS; GARCIA-LOPEZ; GARCIA-CABOT, 2016, p. 316]

Um exemplo dessa abordagem é o website Khan Academy, que incorpora diversos elementos de gamificação como avatares, medalhas, pontos e níveis de progresso:

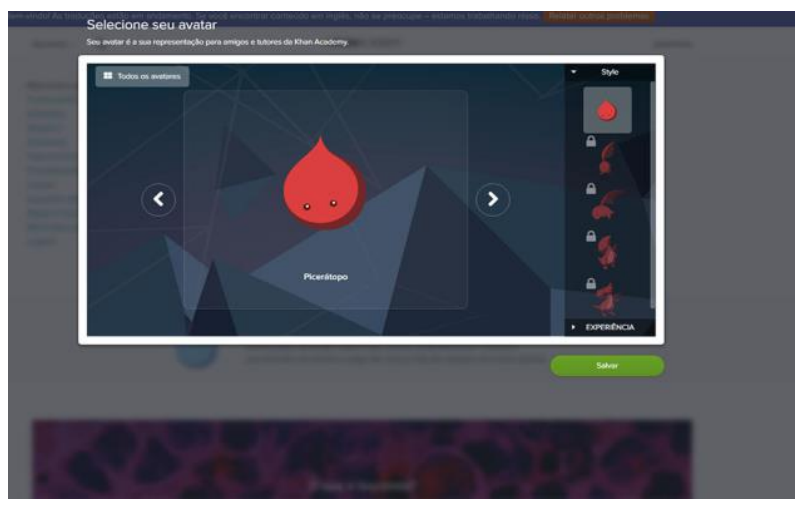

Figura 2: website Khan Academy, seleção de avatar

Simões et al. [2012] sugere guias e objetivos específicos para implantar um processo gamificado oferecendo ferramentas para melhorar o engajamento de alunos. Esse guia inclui ainda um modelo para gamificação social que auxilia os professores, baseado na tabela de mecânicas e dinâmicas do jogo:

\section{Elementos de jogo}

\begin{tabular}{ll} 
Mecânicas de jogo & Dinâmicas de jogo \\
\hline Pontos & Recompensa \\
Níveis & Status \\
Troféus, medalhas & Conquista \\
Bens virtuais & Auto-expressão \\
Leaderboards & Competição \\
Presentes viruais & Altruísmo \\
\hline \hline
\end{tabular}

Tabela 1: Mecânicas de jogo e dinâmias de jogo Fonte: Simões et al. [2012, p. 348], tradução do autor
Realização:
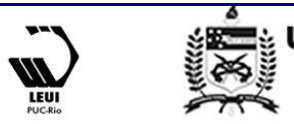


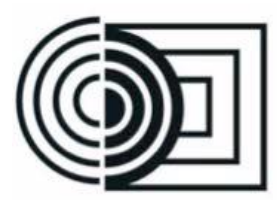

Mecânicas de jogo são o mecanismo para o processo de gamificação, enquanto as dinâmicas de jogo são a motivação despertadas pelas mecânicas equivalentes, culminando em sentimentos.

Entre os tipos de jogos existentes, há uma classificação de "modelo clássico de jogos", atribuída a Juul [2010], que define um jogo como:

Um sistema formal baseado em regras com resultado variável e quantificável, onde diferentes resultados geram diferentes valores, o jogador exerce esforço para influenciar o resultado, o jogador sente-se ligado ao resultado e as consequencias da atividade são opcionais ou negociáveis. [JUUL, 2010, p.5]

Deterding et al. [2011] faz distinções mais específicas sobre jogos e processos gamificados. Comenta que "jogos sérios"são jogos completos que servem a propóstitos que não o de entretenimento, e aplicações gamificadas apenas incorporam esses elementos de jogo. Cita como exemplos o Foursquare (atual Swarm) e segue afirmando que aspectos sociais dos jogos devem ser levados em conta e que os elementos dos jogos quando utilizados na gamificação devem possibilitar interpretações de jogabilidade ao invés de simplesmente serem jogáveis.
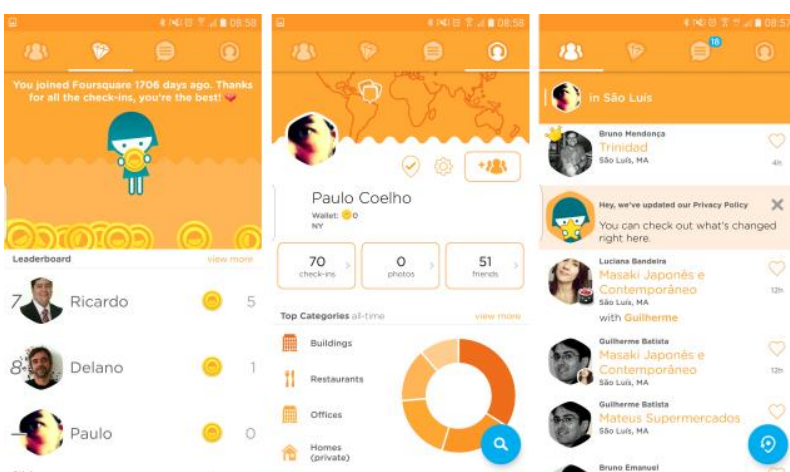

Figura 3: Aplicativo Swarm (antigo Foursquare) e seus elementos de gamificação

Para encontrar que elementos são definidos como pertencentes aos jogos, Deterding et al. [2011] promove uma tabela em que compila os vários níveis dos referidos elementos de design de jogos. Assim, distingue as condições que tornam "jogos sérios" um jogo completo e a gamificação como $16^{\circ}$ Ergodesign - Congresso Internacional de Ergonomia e Usabilidade de Interfaces Humano Tecnológica: Produto, Informações Ambientes Construídos e Transporte

$16^{\circ}$ USIHC - Congresso Internacional de Ergonomia e Usabilidade de Interfaces Humano Computador

CINAHPA | 2017 - Congresso Internacional de Ambientes Hipermídia para Aprendizagem.

parte de um sistema que usa apenas os elementos, não o jogo propriamente dito.

\begin{tabular}{|c|c|c|}
\hline Nível & Descrição & Exemplo \\
\hline $\begin{array}{l}\text { Padrões de } \\
\text { design da } \\
\text { interface de } \\
\text { jogos }\end{array}$ & $\begin{array}{l}\text { Soluções e componentes } \\
\text { de design, comuns e de } \\
\text { sucesso para um } \\
\text { problema conhecido, } \\
\text { incluindo } \\
\text { implementações de } \\
\text { protótipos }\end{array}$ & $\begin{array}{l}\text { Medalhas, quadro de } \\
\text { classificação, níveis }\end{array}$ \\
\hline $\begin{array}{l}\text { Padrões e } \\
\text { mecânicas dos } \\
\text { jogos }\end{array}$ & $\begin{array}{l}\text { Partes normalmente } \\
\text { recorrentes do design de } \\
\text { jogos que dizem respeito } \\
\text { à jogabilidade }\end{array}$ & $\begin{array}{l}\text { Limitação do tempo, } \\
\text { recusros limitados, } \\
\text { turnos }\end{array}$ \\
\hline $\begin{array}{l}\text { Princípios e } \\
\text { heurísticas de } \\
\text { design de jogos }\end{array}$ & $\begin{array}{l}\text { Guias avaliativas para } \\
\text { abordagem de um } \\
\text { problema de design ou } \\
\text { avaliação de determinada } \\
\text { solução de design }\end{array}$ & $\begin{array}{l}\text { Jogo contínuo, } \\
\text { objetivos claros e } \\
\text { variedade de modos de } \\
\text { jogo }\end{array}$ \\
\hline $\begin{array}{l}\text { Modelos de } \\
\text { jogos }\end{array}$ & $\begin{array}{l}\text { Modelos conceituais dos } \\
\text { componentes dos jogos } \\
\text { ou da experiência de } \\
\text { jogos }\end{array}$ & $\begin{array}{l}\text { Mecânica, dinâmica e } \\
\text { estética; desafio, } \\
\text { fantasia, curiosidade; } \\
\text { elementos básicos da } \\
\text { experiência de jogo }\end{array}$ \\
\hline $\begin{array}{l}\text { Métodos do } \\
\text { design de jogos }\end{array}$ & $\begin{array}{l}\text { Práticas e processos } \\
\text { específicos do design de } \\
\text { jogos }\end{array}$ & $\begin{array}{l}\text { Teste de jogos, design } \\
\text { centrado no jogar, } \\
\text { design de jogos } \\
\text { conscientes de valor }\end{array}$ \\
\hline
\end{tabular}

Tabela 2: Níveis de elementos do design de jogos Fonte: [DETERDING et al. 2011], tradução do autor

Finalmente, um paralelo mais claro pode ser traçado entre game design e gamificação, entre o todo e as partes que os compõem e seus propósitos:

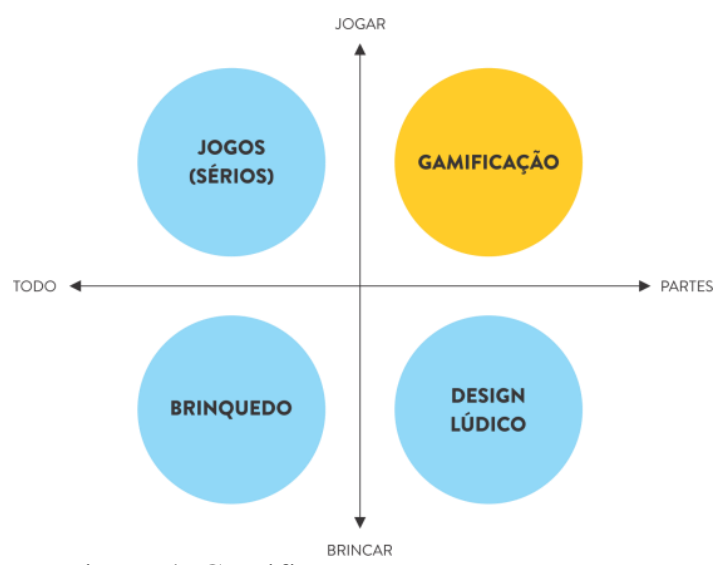

Figura 4: Gamificação entre quatro vetores

Fonte: [DETERDING et al., 2011], tradução do autor
Realização:
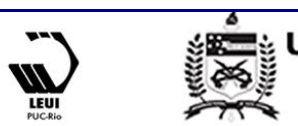


\section{$16^{\circ}$ \\ ERGODESIGN USIHC CINAHPA}

Dentro dessa perspectiva podemos afirmar que jogos sérios são jogos completos e não procedimentos gamificados voltados à educação; que há particularidades dentro do design de jogos que não podem (e não devem) ser excluídas do processo de gamificação como um todo; e que deve-se contextualizar todos os elementos em uma gamificação, mas nunca torná-los específicos devido à grande quantidade de contextos que podem ser utilizados.

\subsection{MUD (Multi User Dungeon)}

Bartle [1996], em seu estudo chamado MUD (Multi User Dungeon), referencia 4 tipos de comportamentos de jogadores: conquistadores, assassinos, socializadores e exploradores. Dentro do gráfico proposto pelo autor, é possível analisar as relações desses jogadores com o mundo criado e com outros jogadores:

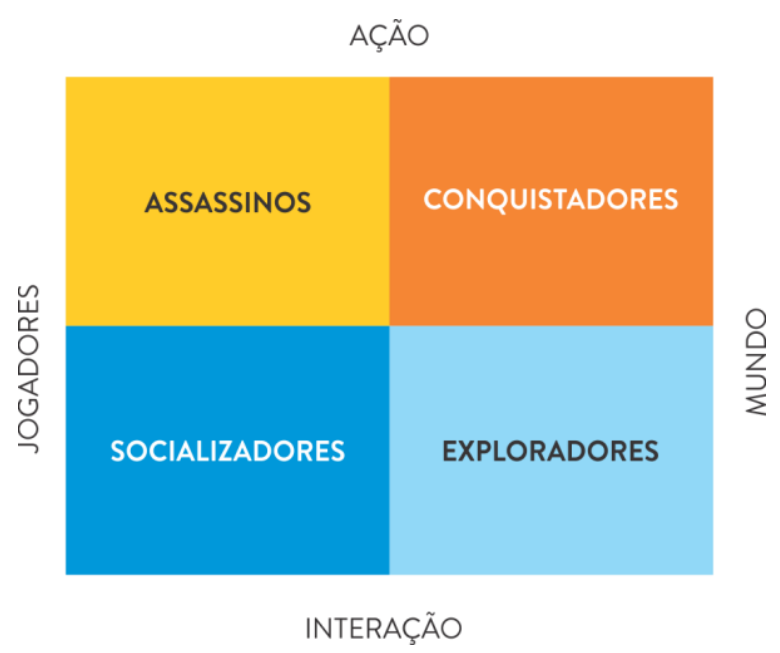

Figura 5: Tipos de jogadores

Fonte: Bartle [1996], tradução do autor

São definidas interações entre cada tipo de jogador, promovendo previsíveis atitudes derivadas desses encontros. Assim, definir o comportamento baseado na liberdade que o ambiente gamificado dá ao jogador possibilita incentivar ou condenar atitudes e garantir o funcionamento esperado do ambiente de jogo [BARTLE, 1996].

Para a realização do presente estudo, foi pensado um cenário em que os jogadores identificavam-se $16^{\circ}$ Ergodesign - Congresso Internacional de Ergonomia e Usabilidade de Interfaces Humano Tecnológica: Produto, Informações Ambientes Construídos e Transporte

$16^{\circ}$ USIHC - Congresso Internacional de Ergonomia e Usabilidade de Interfaces Humano Computador

CINAHPA | 2017 - Congresso Internacional de Ambientes Hipermídia para Aprendizagem.

nas categorias supracitadas a fim de ser produzida uma atividade avaliativa cuja recompensa é uma insígnia de mérito.

A definição de cada categoria foi atingida por afinidade: foram apresentadas quatro categorias de jogos eletrônicos (tiro, simulação, estratégia e aventura) e em seguida os alunos escolheram os jogos com que tinham maior afinidade. Após a escolha, o nome das categorias de jogadores em que se encaixavam foi revelado (assassinos, socializadores, conquistadores e exploradores, respectivamente). Foi mostrado também o quadro de interações entre jogadores (tabela 2), para que pudessem perceber a dinâmica das relações entre o grupo, conforme ilustra a tabela a seguir:

\begin{tabular}{c|c|c|c|c}
\multirow{2}{*}{$\mathrm{C}$} & $\mathrm{C}$ & $\mathrm{E}$ & $\mathrm{S}$ & $\mathrm{A}$ \\
\cline { 2 - 5 } $\mathrm{C}$ & Competição & Perdedores & Tanto Faz & Necessários \\
\cline { 2 - 5 } $\mathrm{E}$ & $\begin{array}{c}\text { Exploradores } \\
\text { Ocultos }\end{array}$ & Respeito & Tanto Faz & Respeito \\
\cline { 2 - 5 } $\mathrm{S}$ & Assunto & Tristes & Iguais & Ódio \\
\cline { 2 - 5 } $\mathrm{A}$ & Presa & Tanto Faz & Desprezo & Evitam
\end{tabular}

Tabela 3: Cruzamento de interações por tipo de jogador. Fonte: Bartle [1996], adaptado pelo autor

O cenário proposto foi o de um universo fantástico, onde criaturas diversas habitam. Cada jogador deveria começar criando sua representação visual nesse universo, destacando os atributos escolhidos em cinco categorias distintas (força, resistência, agilidade, inteligência e sorte). Em seguida foram formados grupos por semelhança de jogadores e foi exigida a criação de um estandarte e um cântico de guerra, que seriam usados em uma suposta competição. Todos os fatores de relacionamento e percepção simbólica de elementos de guerra deveriam ser levados em conta, e foram utilizados para a avaliação dos melhores projetos. Ou seja, os alunos-jogadores deveriam pensar de acordo com os seus personagens e utilizar as referências das aulas de 


\section{$16^{\circ}$ \\ ERGODESIGN USIHC CINAHPA}

semiótica para produzir todo o material visual exigido naquela atividade.

\section{Resultados da pesquisa}

Após a realização das tarefas propostas, os alunos apresentaram suas propostas para alunos de outras disciplinas, como se esses fossem o público fantasioso que julgaria as melhores performances das equipes dentro da narrativa. $\mathrm{O}$ prêmio foram insígnias da personagem, estandarte e cântico, atribuídas tanto para a equipe quanto para o jogador individual.

\subsection{Análise e síntese}

Apesar de ser em uma disciplina do curso de graduação em design, a tarefa exigia muito mais do que a qualidade estética da representação visual dos materiais. A relação entre os signos de guerra e sua aplicação tinha maior importância na avaliação. Representações realistas, mas desconexas da proposta de classe de jogadores, cruzamento de informações e signos de guerra foram mal avaliadas, assim como a falha em representar os próprios signos.

Após a votação, os alunos foram questionados sobre a proposta gamificada dentro da aula. De um total de 26 alunos, 23 (88\%) verbalizaram o interesse por mais aulas similares no decorrer do semestre letivo. 25 alunos (96\%) perceberam o tempo decorrido da tarefa como menor do que realmente foi. 19 alunos (73\%) acharam que a apresentação de um mapa da região ou ilustrações sobre as criaturas que habitam o cenário de fantasia tornaria a tarefa mais interessante ou divertida.

\section{Considerações finais}

Relacionar os elementos de jogos no aprendizado não é simples, tampouco segue alguma fórmula. É necessário compreender as nuances do processo de modo a conseguir de fato imaginá-la como um todo. Sua aplicação só ocorrerá, de maneira completa, a partir daí.

Não devemos, no entanto, julgar que os benefícios da gamificação dentro das salas de aula sejam $16^{\circ}$ Ergodesign - Congresso Internacional de Ergonomia e Usabilidade de Interfaces Humano Tecnológica: Produto, Informações Ambientes Construídos e Transporte

$16^{\circ}$ USIHC - Congresso Internacional de Ergonomia e Usabilidade de Interfaces Humano Computador

CINAHPA | 2017 - Congresso Internacional de Ambientes Hipermídia para Aprendizagem. certos e infalíveis, tampouco milagrosos. Ainda não há estudos definitivos acerca da aprendizagem de contextos educacionais gamificados, embora vantagens sejam facilmente identificáveis.

A tarefa descrita e aplicada no presente artigo ainda precisa ser expandida para outras aulas dentro da disciplina, de modo que sejam validados os processos e obtenha-se a continuidade dos mesmo, permitindo maior planejamento dos elementos de jogo.

A criação de um mapa e sugestões de fauna e flora podem ser adicionados ao estudo, permitindo aos alunos maior imersão e compreensão acerca da tarefa, enriquecendo o aspecto narrativo do universo a ser trabalhado.

Adicionalmente a tarefa pode ser expandida a outras disciplinas que promovam ações criativas e avaliem resultados de acordo com o engajamento dos estudantes. Não limitada a isso, pode ainda ser aplicada e ambientes de autoria de jogos educativos e jogos sérios, na distribuição,, execução e avaliação de tarefas.

Compreender o processo de gamificação na educação auxilia na correta aplicação de seus elementos e suas técnicas, principalmente no retorno de informações do estudante. Jogos e o processo gamificado abrem caminho para maior interação, estimulando a participação de todos os envolvidos no processo educativo.

\section{Referências bibliográficas}

ALESSI, S. M.; R.TROLLIP, S. Learning Principles and Approaches. Boston, MA: Allyn \& Bacon, Inc, 2001.

BUSARELLO, Raul I., ULBRICHT, Vania R., FADEL. Luciane M. A gamificação e a sistemática de jogo: conceitos sobre a gamificação como recurso motivacional. Gamificação na Educação. São Paulo: Pimenta Cultural, 2014. 300p

DE-MARCOS, L.; GARCIA-LOPEZ, E.; GARCIA-CABOT, A. On the effectiveness of game-like and social approaches in learning: Comparing educational gaming, gamification \& 


\section{$16^{\circ}$}

ERGODESIGN USIHC CINAHPA

$16^{\circ}$ Ergodesign - Congresso Internacional de Ergonomia e Usabilidade de Interfaces Humano Tecnológica: Produto, Informações Ambientes Construídos e Transporte

$16^{\circ}$ USIHC - Congresso Internacional de Ergonomia e Usabilidade de Interfaces Humano Computador

CINAHPA | 2017 - Congresso Internacional de Ambientes Hipermídia para Aprendizagem.

social networking. Computers and Education, v. 95, p. 99-113, 2016.

DETERDING, S. et al. From Game Design

Elements to Gamefulness: Defining

"Gamification". Proceedings of the 2011 annual conference extended abstracts on Human factors in computing systems - CHI EA' 11, p. 2425, 2011.

DINEEN, R. Views from the chalk face:

lecturer's and student's perspectives on the development of creativity in art and design. $\mathrm{N}$. Jackson, M. Oliver, M. Shaw \& J. Wisdom. New York: Routledge, 2006.

FREITAS-MAGALHÃES, Armindo. Psicologia da Criatividade: estudo sobre o desenvolvimento da expressão criadora da criança. 7 ed. Porto: ISCE-Edições Universidade Fernando Pessoa, 2003.

GUILFORD, J. P. Way beyond the IQ. Buffalo, New York: The Creative Education Foundation, 1977.

HAWORTH, R.; SEDIG, K. The importance of design for educational games. Education in a technological world: Communicating current and emerging research and technological efforts, p. 518-522, 2011.

JUUL, J. The game, the player, the world: Looking for a heart of gameness. PLURAIS-Revista Multidisciplinar Da UNEB, v. 1, n. 2, p. 1-13, 2010.

MEDNICK, S. A. The Associative Basis of the Creative Proccess. Psychological Review, v. 69, n. 3, p. 220-232, 1962.

MIRANDA, Márcio B., SOUZA, Richard P. L., REMOR, Carlos A. M. A criatividade e a análise de aprendizagem no ensino superior. Criatividade e Inovação na Educação. São Paulo: Pimenta Cultural, 2015. 266p.

MUNGIOLI, A. P. Videogames Como Obras Narrativas : A Arte de Criar Mundos Possíveis. São Paulo: [s.n.].

Realização:

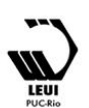

SIMÕES, J.; REDONDO, R. D.; VILAS, A. F. A social gamification framework for a K-6 learning platform. Computers in Human Behavior, 2012. 